\title{
APRENDIZAGEM, ARTE E INVENÇÃo
}

Virgínia Kastrup*

RESUMO. O texto aborda o tema da aprendizagem, usando como referência as contribuições de Gilles Deleuze e Félix Guattari. O objetivo é, tomando como ponto de vista a arte e a invenção, revisitar temas psicológicos clássicos como o hábito, a habilidade e a imitação. O texto sugere o mecanismo da circularidade criadora como chave para o entendimento do processo de aprendizagem inventiva.

Palavras-chave: aprendizagem, cognição, subjetividade.

\section{LEARNING, ART AND INVENTION}

\begin{abstract}
This work investigates the problem of learning, based on the works of Gilles Deleuze and Félix Guattari. The aim of this study was to revisit some classic psychological themes as habit, ability and imitation, from the point of view of art and invention. The text suggests the mechanism of creative circularity to understand inventive learning.
\end{abstract}

Key words: learning, cognition, subjectivity.

O interesse de Deleuze pelo tema da aprendizagem aparece em muitos momentos de sua obra. Em Diferença e Repetição (1968/1988) já é nítido o ponto que marcará a originalidade de sua abordagem: a aprendizagem não é entendida como passagem do não-saber ao saber, não fornece apenas as condições empíricas do saber, nem é uma transição ou uma preparação que desaparece com a solução ou resultado. A aprendizagem, é sobretudo, invenção de problemas, é experiência de problematização. A experiência de problematização distingue-se da experiência de recognição. A experiência de recognição envolve uma síntese convergente entre as faculdades. No caso da percepção, trata-se da síntese da sensação e da memória: esta é a minha casa, o ônibus que pego para ir ao trabalho, o rosto familiar do meu amigo. As sensações ativam um traço mnésico e aí ocorre uma síntese, que é fonte da atividade de reconhecimento, a qual torna o presente, passado, e o novo, velho. Ao contrário, na experiência de problematização as faculdades - sensibilidade, memória, imaginação - atuam de modo divergente. Por exemplo, quando alguém viaja a um país estrangeiro, as atividades mais cotidianas, como abrir uma torneira para lavar as mãos, tomar um café ou chegar a um destino desejado tornam-se problemáticas. Ao ser bruscamente transportado para um novo ambiente, os hábitos anteriores não servem e o viajante vive sucessivas experiências de problematização. Não se trata de mera ignorância, mas de estranhamento e tensão entre o saber anterior e a experiência presente. Quando viajamos somos forçados a conviver com uma certa errância, a perder tempo, a explorar o meio com olhos atentos aos signos e a penetrar em semióticas novas. Somos forçados a pensar, a aprender e a construir um novo domínio cognitivo e uma outra maneira de realizar atividades que eram tão simples e corriqueiras que havíamos esquecido seu caráter inventado. A viagem surge, então, como ocasião de uma aprendizagem, pois o viajante não se dava conta de que as relações que tomava como óbvias e garantidas eram, a rigor, construídas e inventadas. Tal aprendizagem não se esgota na solução dos problemas imediatos, mas prolonga seu efeitos e sua potência de problematização. Quando o viajante retorna à sua cidade, é tomado muitas vezes por uma sensação de estranhamento, tornando-se sensível a aspectos da

Professora Adjunta do Instituto de Psicologia e do Curso de Pós-Graduação em Psicologia da Universidade Federal do Rio de Janeiro.

Endereço para correspondência: Rua Lopes Trovão, 237/801, Icaraí, Niterói-Rio de Janeiro. CEP: $24220-070$. E-mail: vkastrup@nitnet.com.br 
paisagem que normalmente lhe passavam desapercebidos. $\mathrm{O}$ afastamento da cidade, gerado pela viagem, prolonga-se então num afastamento da percepção banal e recognitiva. A abertura da sensibilidade provocada pela viagem para a cidade estrangeira invade, então, a experiência da própria cidade. A experiência de recognição cede lugar à problematização. Os dados da sensibilidade não fazem síntese com os da memória, gerando reconhecimento. Memória e sensibilidade não convergem, mas divergem, gerando uma experiência de estranhamento potencializada pelo frescor da sensibilidade do viajante. Podemos assim dizer, com Deleuze, que a viagem envolveu um aprendizado porque elevou as faculdades ao seu exercício disjunto, ultrapassando os limites do funcionamento recognitivo. É que a aprendizagem começa quando não reconhecemos, mas, ao contrário, estranhamos, problematizamos. $\mathrm{O}$ exemplo do viajante serve também para indicar o que deve ser considerado como o ponto nodal do problema da aprendizagem inventiva, a saber, a circularidade que caracteriza o aprender a aprender.

O objetivo é, em primeiro lugar, apresentar uma certa maneira de colocar o problema da aprendizagem. A aprendizagem foi freqüentemente tratada ao longo da história da Psicologia, e em sua investigação tem predominado o modelo da ciência moderna. A consequiência disto é que a tônica tem recaído sobre a busca de leis da aprendizagem. Esta maneira de colocar o problema revela um caráter limitado desses estudos, pois, se por um lado a aprendizagem é reconhecida como um processo de transformação, seja do comportamento, seja da cognição, o que aponta para sua dimensão temporal, por outro a empresa científica busca as leis e os princípios invariantes que regulam este processo de transformação temporal. Ora, se o processo de aprender encontra-se submetido a leis científicas, seus resultados são passíveis de previsão. O diagnóstico é que o problema da aprendizagem inventiva tem sido sistematicamente excluído da história da Psicologia. Neste campo, a aprendizagem encontra-se dissociada da invenção ${ }^{1}$.

Esta forma de tratar o problema comparece tanto nas concepções de uma aprendizagem mecânica - abordagem behaviorista - quanto naquelas de uma aprendizagem inteligente - abordagem gestaltista (Skinner, 1981; Köhler, 1968). A situação dos trabalhos de Jean Piaget é um pouco mais complexa, pois o tema da aprendizagem remete àquele do desenvolvimento da inteligência, caracterizado por uma sequiência invariante de estágios. Para uma análise mais detalhada da contribuição de Piaget e de seus limites em relação ao estudo da invenção, ver Kastrup, 1999.
Tomando como referência a filosofia de Bergson (1907/1948), a invenção caracteriza-se por dois aspectos. Em primeiro lugar, a invenção é sempre invenção de novidade, sendo, por definição, imprevisível. Em segundo lugar, para Bergson a invenção, em sentido forte, é sempre invenção de problemas e não apenas invenção de solução de problemas. São esses dois pontos - o caráter imprevisível do processo de aprender e a invenção de problemas - que necessitam ser incluídos no estudo da aprendizagem inventiva. É com o intuito de enfrentar este problema, de ligar de maneira indissociável o aprender e o inventar, que recorremos aos textos de G. Deleuze e F. Guattari. O objetivo é analisar temas como o hábito, a habilidade e a imitação, procurando repensá-los a partir da perspectiva dos estudos da produção da subjetividade. O propósito é também examinar alguns pontos envolvidos na aprendizagem inventiva, a saber, o papel desempenhado pela inteligência e o problema do ambientalismo.

\section{HÁBITO E SUBJETIVIDADE}

Para a Psicologia o hábito é um comportamento, um fenômeno observável. Falamos do nosso hábito de escovar os dentes, de tomar banho, de pegar o ônibus para ir ao trabalho e outros. Sua aquisição é explicada pela combinação ou pelo somatório de reflexos, ou seja, pelas ações do organismo. É agindo que formamos nossos hábitos. Para Deleuze (1968/1988), entretanto, o hábito é, antes de tudo, uma contração. Baseando-se em Hume e Bergson, afirma que ele se forma com a contração da repetição de casos ou instantes sucessivos e independentes. Tais casos, que constituem uma repetição material, sofrem uma retenção. $O$ primeiro caso não desaparece, sendo retido até que o segundo apareça. É o hábito que retém os casos no presente. Ele é uma síntese passiva, a primeira síntese do tempo. A coexistência do presente com o passado imediato cria uma tendência à continuação e à perseveração, inclinando para o futuro. A fusão dos casos independentes e sucessivos gera uma experiência qualitativamente nova. $\mathrm{O}$ hábito, na medida em que introduz a diferença na repetição, é a condição da experiência e da subjetividade. Este responde pela criação do si, mas a abordagem psicológica do hábito deixa intratado este problema fundamental, a saber, a emergência do subjetivo, a invenção da subjetividade (Eirado, 1998).

Deleuze afirma que formamos hábitos contemplando, com o intuito de separar a gênese do hábito da ação concreta. Para ele, esta é a condição da ação, ao invés de a ação ser a condição do hábito. 
Afirma ainda que o hábito é a "fundação de que derivam todos os outros fenômenos psíquicos" (1968/1988, p.140). A ação tem um lugar na aprendizagem, dizendo respeito sobretudo à constituição do campo problemático, que é formado pelo problema e por suas condições de resolubilidade. Mas a ação motora, por si só, não substitui o privilégio da sensibilidade como origem da aprendizagem (ibidem, p.239). Esta será, antes de tudo, uma aprendizagem da sensibilidade. Não esqueçamos, contudo, que a sensibilidade não é apenas receptiva, mas contrativa. A ênfase na passividade busca sublinhar o caráter espontâneo da formação dos hábitos. Formamos hábitos contemplando, expondonos aos casos e acasos.

A fórmula "o sujeito tem hábitos" indica uma falsa precedência do sujeito em relação ao hábito. Ao contrário, é o hábito que constitui o sujeito, e é neste sentido que ele se encontra no plano das condições, e não no dos fenômenos observáveis. $\mathrm{O}$ caráter passivo do hábito indica também que o sujeito nada faz para ter hábitos, mas a contração faz-se independente dele e mesmo o forma. Há uma "máquina de contrair" (ibidem, p.140) que não é subjetiva, mas subjetivante. Neste sentido, Deleuze afirma que o "paradoxo da repetição" é não se pode falar em repetição senão pela mudança que ela introduz no sujeito que a contempla (ibidem, p.127). Os hábitos definem toda a nossa relação com o tempo: nossos ritmos, intervalos, tempos de reação e nossas fadigas. Criam também uma disposição para agir e, mais do que isto, para buscar certas situações em que eles possam se realizar (Eirado, 1998). Eles também orientam futuras aquisições, pois criam limites, indicando que não se pode aprender qualquer coisa em qualquer tempo. No tratamento do problema do hábito, vemos a presença da circularidade a que nos referimos no exemplo do retorno do viajante.

O hábito é condição da experiência, mas esta condição é, ela própria, condicionada pela sua realização, pelos seus produtos, num movimento de retroação inventiva. Condição processual, e não invariante, condição concreta, e não abstrata; enfim, condição que é condicionada. É importante notar que não falamos aqui de condições históricas, mas de um modo de funcionamento, de uma espécie de mecanismo da aprendizagem inventiva. A contração dos hábitos é também contração de subjetividade, de atitude, de disposição. Trata-se, aqui, de uma disposição que condiciona, sem determinar, futuras experiências e futuras aquisições. Há, desta forma, uma circularidade inventiva entre condição e condicionado, entre processo e produto, entre problema e solução, que revela a chave do aprender a aprender.

\section{A APRENDIZAGEM DOS SIGNOS E O PAPEL DA INTELIGÊNCIA}

Em Proust e os signos (1987) Deleuze defende, mais uma vez, e agora em primeiro plano, o problema da aprendizagem. Este surge de frente quando da definição da obra de Marcel Proust Em busca do tempo perdido como um romance sobre a aprendizagem, e não sobre a memória, como é em geral considerada. Deleuze refere-se a ela como o relato do aprendizado de um homem de letras. Formula-se a pergunta: o que a aprendizagem da literatura e da arte tem a ensinar acerca da aprendizagem? Esta questão é importante, pois quando falamos em aprendizagem inventiva não entendemos a invenção como algo raro e excepcional, privilégio exclusivo de artistas ou mesmo de cientistas. O interesse é pensar a inventividade que perpassa o nosso cotidiano e que permeia o funcionamento cognitivo de todos nós, do homem comum. É justamente a partir desse interesse que o pensamento de Deleuze convida à adoção da arte como uma perspectiva, como um ponto de vista a partir do qual a aprendizagem é problematizada.

Deleuze afirma: "a arte é o destino inconsciente do aprendiz" (ibidem, p.50). Este destino, este ponto de vista, não se considera como uma meta consciente ou como uma regulação da vontade. Também não se trata de ter na arte, ou numa certa obra de arte, um alvo, um ponto fixo a ser atingido, e que orientaria o processo de aprender. Como ficará mais claro adiante, a arte não é um alvo, mas um atrator caótico, um ponto que é tendencial, sem ser fixo e sem possibilitar falar em regimes estáveis ou em resultados previsíveis. Colocar o problema da aprendizagem do ponto de vista da arte é colocá-lo do ponto de vista da invenção. A arte surge como um modo de exposição do problema do aprender. Esta maneira de penetrar no campo da aprendizagem, pela precisa colocação do problema, significa aplicá-la ao próprio objeto de nossa investigação, ou seja, entender que toda aprendizagem começa com a invenção de problemas. Esta advertência serve de indicação para não repetirmos os equívocos da Psicologia da Aprendizagem, que saltou este momento fundamental, reduzindo-a a um processo de solução de problemas.

O livro de Deleuze sobre Proust constitui um vasto e extenso trabalho sobre o conceito de signo, que fornece, nesta obra, referência para se pensar a invenção de problemas. As idéias centrais são duas: o 
objeto de um aprendizado são os signos e o objetivo de um aprendizado é a interpretação de signos, explicitando seu sentido. De saída, é preciso esclarecer que para Deleuze o conceito de signo não equivale ao de signo lingüístico, que em Saussure é composto de significante e significado. Para Deleuze (1987) os signos se organizam em diferentes sistemas, entre os quais se encontra a linguagem. Afirma que aprender é considerar uma matéria ou um objeto como se estes emitissem signos a serem decifrados (ibidem, p.4). Aprender marcenaria é ser sensível aos signos da madeira; aprender medicina é ser sensível aos signos da doença; aprender a cozinhar é ser sensível aos odores, às cores, às texturas dos ingredientes da comida; aprender a jogar futebol é ser sensível aos signos da bola, do campo, da torcida, dos jogadores. Poderíamos multiplicar os exemplos, mas no momento basta sublinhar que tudo que nos ensina alguma coisa emite signos, e não se aprende senão por decifração e interpretação.

Segundo Deleuze, o signo é aquilo que exerce sobre a subjetividade uma ação direta, sem a mediação da representação. Os signos são emitidos por matérias, objetos, pessoas, mas não são formas, objetos ou sujeitos. Os signos são um tipo de qualidade, de essência ou diferença que existe no seio de qualquer matéria, e não apenas na matéria linguística. Podem ser extraídos da madeira, de um corpo doente, dos ingredientes da culinária, do campo de futebol e assim por diante. Eles revelam a presença da diferença no âmbito do objeto, seu diferencial. O signo é inequívoco em sua presença, mas é equívoco em seu sentido. Através dele captamos a fluidez da matéria, mais do que a solidez do mundo dos objetos conhecidos. O signo aparece, temos certeza de que ele nos atinge de fora, mas não sabemos ainda qual o seu sentido. Possui a força de uma interrogação que força a pensar, de um problema que exige solução. Por isto Deleuze aponta seu caráter de força, coação e violência. Possui um caráter fortuito, mas, por sua força de problematização, impõe-se como inevitável.

Segundo Deleuze e Guattari a aprendizagem também não tem no sujeito o seu centro, mas ocorre numa zona adjacente, situada ao lado das formas subjetivas existentes. Trata-se de um plano impessoal e múltiplo, denominado plano de produção da subjetividade (Guattari \& Rolnik, 1986). É composto de forças tendenciais heterogêneas, movimentos esboçados, fluxos moventes, fragmentos, multiplicidades, diferenças que coexistem com a forma subjetiva existente, mas sem serem subsumidos por ela. O plano de produção da subjetividade é o diferencial do sujeito. Justamente este plano é que é acionado no processo de aprendizagem. Nele se tocam o diferencial do sujeito e o diferencial do objeto. A aprendizagem não se dá no plano das formas, não se trata de uma relação entre um sujeito e um mundo composto de objetos. Ao contrário, faz-se num encontro de diferenças, num plano de diferenciação mútua, em que tem lugar a invenção de si e do mundo. Sujeito e objeto são efeitos, e não pontos de partida ou pólos pré-existentes, pois o signo se expressa numa matéria, mas não é objetivo; afeta o sujeito, mas não é subjetivo. Sem ser objeto de recognição, força o movimento da subjetividade.

Quando somos tocados pelo signo, pela diferença, temos uma experiência de problematização, de invenção do problema. Só a partir daí ocorre a busca de solução e de sentido. Ao acaso dos encontros segue-se a necessidade imposta pelo que nos força a pensar. Aprendemos por coação, forçados pelos signos, ao acaso dos encontros. Segundo Deleuze, quando a inteligência intervem na busca de sentido, é sempre depois da ação dos signos (Deleuze, 1976/1987, p.23), uma vez que a inteligência é um processo de solução de problemas e não de invenção de problemas.

É importante, então, sublinhar que a aprendizagem inventiva nunca se restringe ao plano da inteligência. A inteligência participa, mas não é por sua participação que a verdadeira aprendizagem se dá. A inteligência atua, tem um papel no processo de aprendizagem, mas ela é acionada, forçada pelo encontro com os signos. Neste sentido, é oportuna a distinção estabelecida por Bergson (1932/1992, p. 42) entre uma inteligência que trabalha "a frio" e uma inteligência que trabalha "a quente". A primeira opera analisando e sintetizando, enquanto a segunda é movida por algo de não intelectual, que Bergson (1932/1992) denomina emoção criadora. Esta não equivale a um tom subjetivo ou a um colorido afetivo que se seguiria à representação, mas precede e exige representações. Ela diz respeito a um contato imediato com algo que é exterior ao sujeito e que lhe provoca um abalo afetivo, uma agitação que é criadora na medida em que é exigente de representações que a ela se seguirão. Bergson (1902/1990) falou também extensamente sobre este tema em seu artigo sobre o esforço intelectual. Refere-se aí a trabalhos intelectuais distintos, em diversos graus de esforço ou complexidade. Num dos extremos encontramos o trabalho sem esforço, que é reprodutivo e encadeia representações, num funcionamento automático. No outro extremo temos a inteligência que opera com esforço, a qual podemos dizer que corresponde à inteligência que trabalha a quente e é acionada nos 
processos de invenção. $\mathrm{O}$ esforço advém da transformação de uma idéia - o problema - em imagens materiais - soluções do problema. A força que move a criação de um poema, por exemplo, precisa ser encarnada numa matéria lingüística. É preciso acessar a fluidez que a linguagem, como qualquer matéria, possui. Da mesma maneira, fazer uma escultura é extrair do bronze ou do mármore uma fluidez para criar um braço que pende, um olhar, um desalinho dos cabelos, um corpo em estado de relaxamento, a elegância de um passo de dança. Esculpir é, então, acessar a ductilidade da matéria, suas forças intrínsecas, seu movimento interno. Bergson aponta ainda que há um trabalho de vaivém entre o problema e a solução, pois as imagens que lhe dão forma concreta retroagem sobre a idéia inicial, transformando-a. O exemplo evocado por Bergson é o fato de a idéia original que move a criação de um romance ser afetada e reconfigurada pelos personagens. Inicialmente inventados, os personagens ganham em seguida autonomia, exigindo e mesmo impondo rumos à história, os quais não haviam sido previstos pelo próprio escritor. Na consideração de um movimento de retroação da solução sobre o problema vemos aparecer, mais uma vez, a circularidade inventiva, que constitui a chave para o entendimento da imprevisibilidade dos resultados de um processo de aprendizagem.

Para Deleuze a descoberta fundamental é que a essência do signo, e sua diferença, é irredutível, quer ao sentido objetivo, quer ao sentido subjetivo. É aí que a arte surge como uma perspectiva, como um ponto de vista. Segundo Deleuze, o aprendizado temporal converge para a arte: os signos da arte possuem uma superioridade em relação aos demais. O privilégio concedido aos signos da arte explica o desenvolvimento ou a progressão do processo de aprendizado. A arte impõe-se como um ponto de vista, retroagindo sobre os outros domínios de signos. $\mathrm{O}$ que torna os signos da arte privilegiados em relação aos demais é a maior potência da diferença que portam. $\mathrm{O}$ amarelo dos girassóis de Van Gogh é um amarelo puro, novo, denso e inquietante, que não é objeto de um reconhecimento. $\mathrm{O}$ amarelo de Van Gogh não é recognitivo, mas problemático. Mas, uma vez experimentado, faz-nos ver o nosso mundo diferentemente. Da mesma maneira, as mulheres extremamente gordas, grotescas, acolhedoras e generosas dos filmes de Felline, após produzirem estranhamento no espectador, são em seguida percebidas nas ruas, nos arredores da nossa casa, como personagens de uma percepção artística. Esses exemplos ressaltam o efeito de retroação da arte sobre a vida, fruto de uma aprendizagem inventiva, que acaba por fazer da arte um ponto de vista. Fica claro, então, que este ponto de vista não é o de um sujeito, mas o da diferença e o da invenção. Com isto a abordagem deleuziana da aprendizagem realiza a critica ao subjetivismo e ao culto ao eu, bem como a crítica ao objetivismo e ao ambientalismo. Constitui, por isso, um desvio, tanto em relação às perspectivas subjetivantes quanto àquelas que vêem na aprendizagem um processo de assujeitamento a um suposto mundo dado.

\section{OS LIMITES DA APRENDIZAGEM: O CONCEITO DE TERRITÓRIO E O PROBLEMA DA AQUISIÇÃO DAS HABILIDADES}

Em Mil Platôs (Deleuze \& Guattari, 1997) a aprendizagem ressurge trabalhada através do conceito de território, pelo qual podemos compreender melhor a crítica à perspectiva ambientalista. É que a produção da subjetividade não pode ser concebida sem o seu correlato, que é a invenção do mundo (Kastrup, 2000). Aprender não é adaptar-se a um meio ambiente dado, a um meio físico absoluto, mas envolve a criação do próprio mundo. A noção de Unwelt, de J. von Uexküll, é utilizada por Deleuze e Guattari para compor o conceito de território. O conceito de Umwelt significa meio de comportamento próprio a um organismo, mundo próprio ou ambiente de vida, e é distinto de Umgebung - meio geográfico ou físico - e de Welt - universo da ciência. A preocupação do biólogo Uexküll é mostrar que o animal percebe apenas uma fração do meio que o rodeia, o que configura os limites de sua ação (Canguilhem, 1976). Nos termos de Deleuze e Guattari, o território define e é definido pelo organismo, numa construção recíproca.

O papel do território é fundamental na aprendizagem, pois aponta o problema dos seus limites. A ciência cognitiva contemporânea também reconhece a importância da criação de um contexto ou domínio cognitivo. Na obra de H. Maturana e F. Varela, que concebem uma cognição autopoiética (Maturana \& Varela, 1990) ou enactiva (Varela, 1989), tem-se o testemunho do esforço da ciência contemporânea em abordar o co-engendramento, a invenção recíproca e indissociável do si e do mundo, bem como a invenção de problemas. Também nessa direção Dreyfus (1992) trata, de maneira interessante e detalhada, do desenvolvimento de habilidades ou competências, oferecendo a descrição do processo de aprender a dirigir um automóvel e jogar xadrez. Não 
se trata apenas de aprender a fazer algo, mas de fazêlo bem, com destreza, mestria e perícia. A preocupação de Dreyfus é mostrar que aprender não é dominar regras, princípios abstratos ou programas de ação (como defende o cognitivismo computacional), mas desenvolver uma competência sensório-motora fina e contextualizada. Tomemos o exemplo de dirigir um automóvel. A aprendizagem inicia-se quando o instrutor transmite regras que dizem respeito às funções dos pedais e ao uso do volante, além de instruções gerais sobre velocidade e distância, ainda abstraídas do complexo ambiente do trânsito. O novato procura aplicar tais regras realizando tarefas específicas. A aprendizagem avança com a tomada em consideração de um número crescente de elementos do ambiente, que passam a compor o contexto onde a ação se dá. Aos traços não-situacionais se acrescentam traços situacionais, como por exemplo certo ruído do motor que exige a troca da marcha, a posição e a atitude de pedestres e motoristas, tais como distração, impaciência, vigilância ou embriaguez. Para Dreyfus há uma conversão progressiva da conduta abstrata e geral do motorista numa conduta concreta e contextual, atingindo finalmente o que é descrito como "conduta intuitiva" e que substitui aquela guiada por representações. A perícia requer refinamento sensorial e fluidez de movimentos. Não se trata do reconhecimento de formas, mas do contato e da apreensão de uma matéria fluida e irrepresentável e de certos signos provenientes do ambiente. O interessante do trabalho de Dreyfus é indicar, de maneira clara, que a progressão do processo de aprendizagem envolve um expurgo da representação e a longa conquista do contato imediato com a fluidez da matéria.

Quando Deleuze \& Guattari (1997) formulam o conceito de território, é apontada, de saída, sua perspectiva estética. O território configura limites para a ação, limites que não são topográficos, mas semióticos. Através da aprendizagem de semióticas locais e específicas são configuradas fronteiras de conexão com o ambiente. Ao falar de semióticas que são formadas ao longo de um processo de aprendizagem, falamos de uma aprendizagem territorial. Aprender não é somente ter hábitos, mas habitar um território. Habitar um território é um processo que envolve o "perder tempo", que implica errância e também assiduidade, resultando numa experiência direta e íntima com a matéria. Não basta o decorrer do tempo cronológico, embora a repetição da experiência ao longo do tempo seja uma condição necessária. $\mathrm{O}$ habitante de um território não precisa passar pela representação. $\mathrm{O}$ habitar resulta numa corporificação do conhecimento ${ }^{2}$, envolvendo órgãos dos sentidos e também músculos. Habito o território onde me sinto em casa, tenho habilidades e realizo movimentos que parecem espontâneos. No caso do hábito, há uma prevalência da sensibilidade sobre a ação concreta; no caso da habilidade, toca-se diretamente na face de solução de problemas que a aprendizagem envolve, pois a habilidade envolve um saber-fazer, uma ação efetiva. O manejo habilidoso é um agir em fluxo, uma lida com as coisas e as situações, uma atividade e uma prática. No entanto, é preciso atentar para o fato de que tanto a invenção de problemas quanto a solução de problemas estão aí presentes.

Esta idéia aparece no conceito de agenciamento. Deleuze \& Guattari (1995) indicam que nosso acoplamento com o mundo externo não é uma relação entre formas ou termos pré-dados, mas um agenciamento, uma comunicação entre fluxos ou forças heterogêneas que possui duas faces. Por um lado, é agenciamento maquínico de corpos, que põe em relação imediata fluxos diversos: técnicos, políticos, biológicos, lingüísticos, etc. No caso do agenciamento com um dispositivo técnico, o usuário e o dispositivo formam uma só máquina, em sintonia, numa circulação de afetos e efeitos recíprocos. Os fluxos em proximidade imediata circulam numa zona de indiscernibilidade e osmose. $\mathrm{O}$ conceito de agenciamento maquínico vem justamente marcar o caráter de produção deste acoplamento fino e molecular, cuja suavidade do resultado esconde sua origem. $\mathrm{O}$ termo maquínico serve para lembrar esta origem que tendemos a esquecer.

Por outro lado, o agenciamento é coletivo, e isto em dois sentidos. O mais óbvio remete à dimensão social presente em todo agenciamento, inclusive o agenciamento técnico. Por exemplo, não podemos

\footnotetext{
O caráter sensório-motor do conhecimento foi largamente trabalhado por J. Piaget. No entanto, Piaget (1978) considera que o desenvolvimento cognitivo segue o curso do concreto para o abstrato, da inteligência sensório-motora para o pensamento lógico-formal. $\mathrm{O}$ ponto de vista epistemológico, adotado por Piaget, distingue sua abordagem da aprendizagem daquela de Deleuze e Guattari, que tratam do ponto de vista da arte. No campo das ciências da cognição, encontramos em F. Varela a consideração de que o caráter corporal e concreto do conhecimento não é uma etapa a ser ultrapassada. O tema da corporificação do conhecimento é amplamente tratado por F. Varela em sua abordagem da cognição enactiva ( cf. Varela, Thompson e Rosch, 1993; Varela, 1995). Para um exame das proximidades entre Deleuze e Guattari, e Varela e Maturana, ver Kastrup, 1995; 1998.
} 
pensar o agenciamento com o livro sem levar em conta a complexa rede social, política, econômica, de instituições e saberes que subsiste e constrange as práticas de leitura. Neste sentido, o dispositivo técnico livro é uma peça de uma engrenagem social. O segundo sentido de "coletivo" não é tão óbvio, mas é talvez o mais importante. O agenciamento é coletivo não apenas porque remete a um socius, para além do indivíduo, mas também porque remete a uma multiplicidade, que subsiste aquém do indivíduo. Assim, o agenciamento é dito coletivo porque opera num nível distinto do das formas unificadas e visíveis - sujeito, objeto, representação - onde circulam processos, forças, intensidades, afetos. Os agenciamentos ocorrem neste plano molecular, e não no nível molar das formas percebidas.

É também neste plano que a aprendizagem inventiva tem lugar. Seu desenvolvimento é sempre resultado da tensão entre as formas existentes, constituídas historicamente, e os abalos, as inquietações, os estranhamentos que nos afetam. Somos inquietados, sofremos abalos, somos vitimados pelo estranhamento. Trata-se aí, sem dúvida, de uma passividade. Mas há que se distinguir dois tipos de passividade. A primeira é aquela do movimento reflexo, quando sou compelido a me mover. É a passividade do movimento que efetuo quando da introdução de um eletrodo que estimula meu cérebro. Neste caso, trata-se de um movimento compulsivo e mecânico, que não deixa margem para resistência, de uma situação que poderia ser dita de escravidão do músculo ao estímulo. Mas há uma outra modalidade de passividade. O exemplo é um jogador de futebol que se entrega às forças e aos signos que experimenta no campo perceptivo, deixando-se mover e levar por elas. As ações que o jogador deve realizar são constrangidas por forças do presente, e seu desempenho não se esgota no recurso às regras do jogo. A experiência anterior não comparece pela busca ativa na memória, pela evocação voluntária e consciente, mas por uma prontidão corporificada pelas aprendizagens anteriores. A perfeita sintonia com as forças experimentadas no presente caracteriza um movimento passivo, mas que não é reflexo ou mecânico. Trata-se de uma sintonia fina, molecular e maquínica, pois gera jogadas novas, inusitadas e imprevisíveis. É neste segundo sentido que a passividade da aprendizagem inventiva deve ser compreendida. Trata-se, mais uma vez, da circularidade entre invenção de problema e solução de problema, de sensibilidade e ação, intricadas de modo complexo.
É importante sublinhar também que quando nos situamos no campo da invenção não estamos no domínio da espontaneidade. A aprendizagem inventiva não é espontânea, mas sim constrangida, não apenas pelo território que já habitamos mas também pelo presente que experimentamos. O presente exige uma atenção aos signos que, nos termos de Bergson (1934/1979), é uma atenção suplementar, atenção à duração, para além da função e do valor de uso do objeto em questão, para além dos esquemas práticos da recognição. Pode-se dizer que essa atenção suplementar implica mesmo uma desatenção ao caráter utilitário da vida prática. Em outras palavras, há uma disciplina envolvida na aprendizagem inventiva. Esta idéia pode parecer, à primeira vista, contraditória com a invenção, aparentemente afeita à espontaneidade. Mas atribuir a disciplina apenas à aprendizagem mecânica é por certo confundir a noção de disciplina com a de controle. A disciplina diz respeito à necessidade de embarcarmos obstinadamente nos fluxos materiais, atentos à sua singularidade. No campo da disciplina, estamos entregues às forças ou aos signos da matéria em questão. $\mathrm{O}$ desenvolvimento das habilidades depende de uma prática com as coisas, o que envolve utilizálas, modificá-las e até destruí-las. Assim desenvolvemos aptidões e formamos conhecimentos inscritos corporalmente. A disciplina é uma condição, embora não garanta que a invenção se cumpra.

A noção de controle remete a uma relação extrínseca, antes com as pessoas do que com os fluxos materiais. O controle busca impor regras de ação a partir do exterior: controle do tempo, sistema de recompensas e punições, protocolos de avaliação e outras estratégias. O controle faz do aprendiz um sistema heterônomo, controlado por regras extrínsecas, que não foram geradas pelo agenciamento com a matéria. Já a disciplina gera autonomia ${ }^{3}$, ou seja, regras emergentes dos próprios agenciamentos. Em muitas situações concretas de aprendizagem disciplina e controle encontram-se presentes e misturados, mas é importante distingui-los, pois enquanto a atenção ao presente e a prática disciplinada trabalham a favor da aprendizagem inventiva, o controle é seu grande adversário.

A concepção adaptacionista do aprender não leva em consideração, em suas formulações teóricas, a distinção deleuziana entre plano molar e plano molecular, entre as representações e os signos. Sem conceber o trabalho fino realizado no plano molecular,

Para a distinção entre heteronomia e autonomia de um sistema cognitivo, ver Varela, 1989. 
ela limita-se ao plano molar, às dicotomias sujeitoobjeto, organismo-ambiente. A perspectiva que se abre com Deleuze \& Guattari é apontar que há constrangimentos na matéria que não equivalem a imposições de um mundo dado. $\mathrm{O}$ primeiro constrangimento que está em jogo na aprendizagem inventiva está situado no plano molecular dos signos, e não no plano molar das formas. Deleuze (1988) insiste sucessivas vezes que a aprendizagem dos signos envolve não só o acaso dos encontros, mas força a pensar, atuando com violência sobre o pensamento e impondo-se como uma necessidade. A necessidade de que fala Deleuze não se define negativamente, não constitui uma falta, mas é positiva. Trata-se aí de uma necessidade que exprime a abertura de um problema, e não a ausência de uma solução. Ela exprime sua insistência, sua obstinação em se colocar. E o problema se coloca sempre como singular, atingindo-nos de fora. Mas o constrangimento do signo, do presente, é ele também limitado e constrangido pela história das aprendizagens anteriores, pelo saber corporificado pelos hábitos e pelas habilidades. A positividade da necessidade marca aí os limites do presente variável e movente. Presente e passado, problema e solução limitam-se de forma recíproca, atestando a circularidade inventiva a que nos referimos acima. Há uma zona de indeterminação situada entre esses dois limites, a qual é o espaço onde a invenção se dá e que, por sua vez, responde pela imprevisibilidade de seus resultados.

Este duplo limite é referido por Deleuze e Guattari (1975/1977; 1980/1997) quando afirmam que a aprendizagem envolve não apenas processos de territorialização e subjetivação, mas também de desterritorialização e dessubjetivação. Habitar um território é como ser íntimo, mas também ter a possibilidade de acolher o estrangeiro. Para Deleuze e Guattari (1980/1997) só há desterritorialização nos limites, nas bordas de um território. O encontro com os signos, é, então, uma experiência crítica, pois se dá sobre os limites do território que é habitado. O signo põe o problema, força a pensar e exige decifração e sentido, produzindo uma reconfiguração permanente dos limites da subjetividade e do território. Toda aprendizagem inventiva é crítica, no sentido de que concerne aos limites e envolve sua transposição, impedindo o sujeito de continuar sendo sempre o mesmo.

Em resumo, a aprendizagem abarca devires, bem como a corporificação do conhecimento. Seu caráter de devir exige do aprendiz uma errância, um mergulho no mundo da matéria, o que implica um movimento de dessubjetivação, de desprendimento de si e mesmo um sacrifício do eu pré-existente. Seu caráter de corporificação diz respeito ao fato de que a aprendizagem produz uma configuração sensóriomotora que é obtida pela assiduidade com que se habita um território. A formação das habilidades e competências específicas produz a resistência necessária ao desmanchamento das formas e reduz o risco de sua inconsistência, concorrendo para impor limites à flexibilidade, ao risco de a errância converter-se num fim em si mesma. Ambos os aspectos fazem parte da aprendizagem quando esta é entendida como processo de produção da subjetividade.

Tomando emprestada uma idéia de Foucault (1994), pode-se dizer que a aprendizagem inventiva envolve não apenas a dimensão tecnológica de trato com a matéria, mas também um certo ethos, uma atitude. Esta atitude consiste em não tomar a experiência presente, o encontro com os signos, o problema, como algo transitório, fugidio ou contingente, mas em manter ou perpetuar sua força e sua exigência de decifração. À passividade segue-se então um trabalho. $\mathrm{O}$ signo imprime força inicial ao processo, mas há um esforço a mais, que encontra sua fonte num corpo inventivo, que não se furta à exigência do trabalho. Trabalhar com o signo não é anular sua singularidade referindo-o a um plano subjetivo e pré-existente de sentido, mas é praticar um jogo difícil entre o constrangimento imposto por sua singularidade e o exercício da invenção. É transformálo, captando-o naquilo que ele é. A interpretação não destrói a novidade do signo, onde reside sua força, mas respeita-a e viola-a ao mesmo tempo, criando a partir dele e colocando-o sempre à prova. Este modo de relação com o signo é também um modo de relação consigo mesmo. $\mathrm{O}$ aprendiz artista não se conforma com seus limites atuais, mas toma-se a si mesmo como objeto de uma invenção complexa e difícil. O aprendiz é constrangido à tarefa de reinventar-se. A aprendizagem, sob a perspectiva da arte, envolve então uma atitude-limite, que faz escapar da polarização sujeito-objeto, interior-exterior, e habitar a zona de fronteira. A atitude-limite, no caso, não consiste em trabalhar dentro de limites fechados e que não poderiam ser ultrapassados, mas em trabalhar transpondo limites, aprendendo a aprender.

O caráter paradoxal da aprendizagem inventiva é que, além de exigir o "perder tempo" e a errância, ela envolve também, e de modo inelutável, um trabalho, uma repetição, uma disciplina, uma série de experiências, de exercícios e práticas que resultam na formação de hábitos e competências específicas. $\mathrm{O}$ hábito responde por um certo ritmo, uma assiduidade 
na habitação de um território. $\mathrm{O}$ desenvolvimento das habilidades e competências se faz quando o comportamento se torna um pensamento corporificado. Realiza-se um longo detour para reencontrar o imediato, e a conduta do artista parece embaralhar os tradicionais limites da aprendizagem, pois sua fenomenologia traz, do comportamento adquirido, o caráter de construção, mas do inato traz a fluidez e a aparente naturalidade. Esta naturalidade é produzida, mas em sua aparente suavidade esconde o imenso e complexo trabalho de construção da simplicidade. A habilidade ou a competência refere-se a um plano técnico da conduta, que poderia levar a pensar que sua sintonia com um certo território, o agenciamento direto que ela acessa, redundaria numa adaptação especialmente fina ao meio ambiente.

Mas a aprendizagem inventiva não tem a adaptação como seu ponto de vista, e sim a arte. $\mathrm{O}$ salto consiste em desconectar as habilidades e competências do controle do comportamento e da dominação de um suposto mundo dado. Tomando como exemplo a atividade da cozinheira, pode-se dizer que a arte de cozinhar está presente quando a relação com os ingredientes não é regida por regras ou receitas prontas. Cozinhar como artista é inventar novos pratos e novos sabores, lidando com fluxos, cores, odores, texturas, consistências, nuances. Atingir o ponto de vista da arte na cozinha envolveu uma molecularização de sua percepção e de sua ação, todo um aprendizado sensório-motor, toda uma familiaridade com um certo sistema de signos que foi utilizada para a criação de pratos e sabores singulares e inéditos.

\section{A QUESTÃO DO ENSINO-APRENDIZAGEM E A IMITAÇÃO}

O tema da aprendizagem inventiva suscita uma questão: é possível ensinar ou fazer inventar? Mesmo sem respondê-la de maneira definitiva, Deleuze (1968/1988) indica uma direção, que encontra em Gabriel de Tarde, para quem a imitação é uma forma de aprendizagem social, mas que é redefinida através das idéias de contágio e propagação. Isto é uma novidade, pois o tema da imitação havia sido tratado por A. Bandura, por exemplo, como modelação, cujo mecanismo era baseado no controle, no reforço vicariante (Bandura e Iñesta, 1977). Para Tarde, diferentemente, a imitação se faz como propagação ou contágio múltiplo. Stengers (1987) esclarece que a noção de propagação, referida ao domínio da natureza, possui dois sentidos: o físico e o biológico. Em Física fala-se da propagação de um raio de luz ou do calor. A propagação termodinâmica é uma difusão de calor, causada pela diferença inicial de temperatura, e tende a sua uniformização, ou seja, seu desenvolvimento tende a anular a causa que o engendrou. Já nas Ciências Biológicas, a noção ganha o sentido, por exemplo, de propagação de uma epidemia por bactérias ou vírus. Diferentemente da concepção termodinâmica, a propagação biológica tem como efeito propagar a própria origem. "Todo vivo infectado torna-se ele mesmo centro de propagação; cada um torna-se um centro potencial de um novo processo, que não esgota sua causa, mas a regenera à medida que se produz" (Stengers, 1987, p.18). A propagação, aqui pensada do ponto de vista do sucesso do vírus, não fornece uma metáfora, mas sim o entendimento do mecanismo do processo de ensinoaprendizagem, que se dá por pontos de bifurcação, gerando uma grande rede, múltipla e instável.

Deleuze comenta: "Nada aprendemos com aquele que nos diz: faça como eu. Nossos únicos mestres são aqueles que nos dizem: 'faça comigo' e que, em vez de nos propor gestos a serem reproduzidos, sabem emitir signos a serem desenvolvidos no heterogêneo" (1968/1988, p.54). A relação ensino-aprendizagem depende de um mestre que não se furte de sua condição de aprendiz, o que é uma questão de política cognitiva. O plano de sintonia mestre-aprendiz é um campo de criação, uma zona de vizinhança, um espaço híbrido. O mecanismo não é de identificação, mas de contágio e propagação. Não há transmissão de informação, nem interação professor-aluno, mas habitação compartilhada de uma zona de neblina, a zona molecular. Neste campo indiscernível, a fronteira entre o professor e o aprendiz se desfaz. O professor não é o centro do processo ensino-aprendizagem. Situado do ponto de vista da arte, ele faz circular afetos e funciona como um atrator. Além de um emissor de signos, o professor é um atrator de afetos. Trata-se de um atrator caótico, no sentido da física dos sistemas, longe do equilíbrio de Ilya Prigogine (Prigogine \& Stengers, 1990). O atrator é, de modo geral, um tipo de estado ou regime que orienta a evolução temporal de um sistema. A Física clássica descreve atratores estáveis e deterministas como um estado de equilíbrio termodinâmico ou o estado de imobilidade para o qual tende um pêndulo real, funcionando com atrito. Uma vez atingido tal estado, o sistema não se afasta dele espontaneamente. Mas o professor mais se assemelha a um atrator estranho, estudado pela física dos sistemas longe do equilíbrio. Eles não têm a propriedade da estabilidade, mas são caóticos. Os sistemas longe do equilíbrio possuem condições iniciais instáveis. Duas condições vizinhas 
podem engendrar, frente a uma certa perturbação, evoluções diferentes, inventivas e por isto imprevisíveis. O funcionamento do sistema se bifurca, faz uma escolha, ou antes, uma escolha não subjetiva faz-se nele. Além disto, o sistema, ao invés de se estabilizar num estado determinado, apresenta um comportamento de tipo aleatório, incerto, errante. Segundo Stengers (1987, p. 338), os atratores caóticos constituem "menos um modelo do que um ponto de interrogação, um sinal de alerta". A ausência de um modelo de funcionamento deve-se a razões intrínsecas à própria natureza do sistema, ou seja, é porque o processo é inventivo e imprevisível que ele é irredutível a um método ou modelo.

O professor é um atrator, embora o atrator não seja necessariamente um professor. $\mathrm{O}$ atrator é uma função: define-se por seu poder de atrair, de arrastar consigo. Um companheiro pode desempenhar esta função, ou a própria matéria para os auto-didatas. No caso de haver um professor, ele atrai para a matéria, e não para um saber pronto. Ele é alguém que exerce a função de conduzir o processo, a expedição a um mundo desconhecido, de fazer acontecer o contato, de possibilitar a intimidade, de acompanhar, e mesmo de arrastar consigo, de puxar. Não para junto de si, mas para junto da matéria, para o devir da matéria, seguindo, acompanhando sua fluidez. Cada agenciamento professor-aluno é um ponto de bifurcação, de proliferação de possíveis, de multiplicação de fontes, de ramificação. Cada agenciamento abre a possibilidade da continuidade da propagação. Contudo, há um ponto de bifurcação, de indeterminação, e o resultado não é garantido. Por isto não há programa ou método de trabalho para a aprendizagem inventiva. Mas há, seguramente, uma política pedagógica a ser praticada. A política da invenção consiste numa relação com o saber que não é de acumular e consumir soluções, mas de experimentar e compartilhar problematizações, e a adoção da arte como ponto de vista faz parte desta política.

A perspectiva da arte libera a aprendizagem da solução de problemas, que faz da performance adaptada um valor em si. Pode-se concluir que as competências de nada valem se elas apenas intensificam a dimensão de controle do comportamento, e não são capazes de ser um meio de exercício da liberdade de fazer diferentemente, de ser diferentemente, de inventar a si e também a um mundo. O ponto de vista da arte revela-se como uma forma superior de problematização, ou, em outras palavras, significa colocar-se frente ao processo de aprender do ponto de vista da problematização, que define, então, uma forma de relação com os objetos, com os modos de ação e consigo mesmo. O interessante aí é que esta forma de relação, esta atitude, esta política que orienta e dirige o processo de aprendizagem, é um ponto de vista que é, ele próprio, resultante de um processo efetivo de aprendizagem. Trata-se, aí, de aprender a aprender.

\section{REFERÊNCIAS BIBLIOGRÁFICAS:}

Bandura, A. \& Iñesta, E. R. (1977). Modificación de conduta. Mexico: Trillas.

Bergson, H. (1948). L'evolution créatrice. Paris: PUF. (Originalmente publicado em 1907).

Bergson, H. (1979). O pensamento e o movente - Introdução. Bergson. (F. L. e Silva, Trad.). (pp. 99-151). São Paulo: Abril Cultural. (Trabalho original publicado em 1934).

Bergson, H. (1990). L'effort intellectuel. Em H. Bergson. L'énergie spirituelle. (pp. 153-190). Paris: PUF. (Originalmente publicado em 1902).

Bergson, H. (1992). Les deux sources de la morale et de la religion. Paris: PUF. (Originalmente publicado em 1932).

Canguilhem, G. (1976). El conocimiento de la vida. Barcelona: Anagrama.

Deleuze, G. (1987). Proust e os signos. (A. C. Piquet \& R. Machado, Trads). Rio de Janeiro: Forense Universitária. (Trabalho original publicado em 1976).

Deleuze, G. (1988). Diferença e repetição. (L. Orlandi \& R. Machado, Trads). Rio de Janeiro: Graal. (Trabalho original publicado em 1968).

Deleuze, G. \& Guattari, F. (1977). Kafka - por uma literatura menor. (J. C. Guimarães, Trad.). Rio de Janeiro: Imago. (Trabalho original publicado em 1975).

Deleuze, G. \& Guattari, F. (1997). Mil Platôs. (S. Rolnik, Trad.). Rio de Janeiro: Ed. 34 Letras. (Trabalho original publicado em 1980).

Dreyfus, H. (1992). La portée philosophique du connexionnisme. Em D. Andler (Org.), Introduction aux sciences cognitives, (pp. 352-373). Paris: Gallimard.

Dreyfus, H. (s/d) Merleau-Ponty critique of mental representation: the relevance of phenomenology to scientific explanation. Disponível em $\langle$ http://socrates.berkeley.edu/ hdreyfus>. (Acessado em 19/07/2000)

Eirado, A. (1988). Hábito e Invenção. Revista do Departamento de Psicologia da Universidade Federal Fluminense. 10 (1), 4-8.

Foucault, M. (1994). Qu'est-ce que les Lumières?. Em D. Defert \& F. Ewald (Orgs.). Dits et écrits par Michel Foucault, (pp. 562-578). Paris: Gallimard.

Guattari, F. (1992). Caosmose. (A. L. Oliveira \& L. Leitão, Trads.). Rio de Janeiro: Ed. 34 Letras. (Trabalho original publicado em 1992).

Guattari, F. \& Rolnik, S. (1986). Micropolítica: cartografias do desejo. Petrópolis: Vozes. 
Kastrup, V. (1995). Autopoiese e subjetividade: sobre o uso da noção de autopoiese por Deleuze e Guattari. Revista do Departamento de Psicologia da UFF. 7 (1), 87-97.

Kastrup, V. (1998). A cognição contemporânea e a aprendizagem inventiva. Arquivos Brasileiros de Psicologia. 49 (4), 108-122.

Kastrup, V. (1999). A invenção de si e do mundo - uma introdução do tempo e do coletivo no estudo da cognição. Campinas-SP: Papirus.

Kastrup, V. (2000). A produção da subjetividade na era da informática: um retorno ao ambientalismo? Disponível em <http://www.psicologia-online.org.br/psicoinfo.html>. (Acessado em 08/06/1998)

Köhler, W. (1968). A psicologia da gestalt. Belo Horizonte: Itatiaia.

Maturana, H. \& Varela, F. (1990). El arbol del conocimiento. Madrid: Debate.

Piaget, J. (1978). A epistemologia genética. Em Piaget. (N. Caixeiro, Trad.). (pp. 1-64). São Paulo: Abril Cultural. (Trabalho original publicado em 1970).
Prigogine, I. \& Stengers, I. (1990). Entre o tempo e a eternidade. Lisboa: Gradiva.

Skinner, J. B. (1981). Ciência e comportamento humano. São Paulo: Martins Fontes.

Stengers, I. (1987). D'une science a l'autre. Paris: Seuil.

Tarde, G. (s/d). As leis da imitação. Lisboa: Rés.

Varela, F. (s/d). Conhecer: ciências cognitivas - tendências $e$ perspectivas. Lisboa: Instituto Jean Piaget. (Originalmente publicado em 1988).

Varela, F. (1989). Autonomie et connaissance. Paris: Seuil.

Varela, F. (1995). Sobre a competência ética. Lisboa: Edições 70.

Varela, F., Thompson, E. \& Rosch, E. (1993) L'inscription corporelle de l'esprit. Paris: Seuil.

Recebido em 22/02/2001

Revisado em 23/04/2001

Aceito em 30/05/2001 